\title{
Growth Performance and Feed Utilization of Russian Sturgeon Acipenser gueldenstaedtii Brandt\&Ratzeburg, 1833 in Grow-out Phase Cultured in the Black Sea
}

\author{
Mehmet Kocabaş $^{1 *}$, Nadir Başçinar ${ }^{2}$, Şebnem Atasaral Şahin ${ }^{2}$, Ramazan Serezli $^{3}$ \\ ${ }^{1}$ Department of Wildlife and Fisheries, Faculty of Forestry, Karadeniz Technical University, 61080 Trabzon, Turkey. \\ ${ }^{2}$ Department of Fisheries Technology Engineering, Faculty of Marine Sciences, Karadeniz Technical University, 61530 Trabzon, Turkey \\ ${ }^{3}$ Department of Aquaculture, Fisheries Faculty, Katip Çelebi University, 35620 İmir, Turkey
}

\section{A R T I C L E I N F O}

Article history:

Received 22 May 2015

Accepted 17 August 2015

Available online, ISSN: 2148-127X

Keywords:

Russian sturgeon

Acipenser gueldenstaedtii

Grow-out phase

Growth performance.

Feed utilization

\section{A B S T R A C T}

The aim of present study was to determine the growth performance of Russian sturgeon Acipenser gueldenstaedtii throughout 5 years and to investigate problems encountered in grow-out phase. Fish samples $(2750.88 \pm 351.18 \mathrm{~g}, 80.18 \pm 6.49 \mathrm{~cm}$ mean \pm SD) were equally stocked into fiberglass tanks, three replicate per treatment and fed for 5 years. Gain of weight and length, Specific Growth Rate (SGR), Condition Factor (CF) and Feed Conversion Ratio (FCR) were determined. Our results indicated that mean final length and weight were $106.34 \pm 2.79(\mathrm{~cm})$ and $6651.16 \pm 3.16(\mathrm{~g})$. The mean condition factor (CF) at year 5 was 0.51 . FCR values fluctuated and the highest value of food conversion rate (FCR) was determined in $4^{\text {th }}$ year. During the rearing period of Russian sturgeon, SGR values decreased dramatically from 2.88 to 1.83 . In conclusion, slow growth was determined in Russian sturgeon A. gueldenstaedtii. Therefore, there is need for extensive evaluation and comparison of data obtained from field studies and those obtained from laboratory studies.

${ }^{*}$ Corresponding Author:

E-mail: mkocabas@hotmail.com

\section{Introduction}

Russian sturgeon Acipenser gueldenstaedtii is one of the freshwater fish species with the greatest importance on a commercial scale in world (Moini et al., 2012) and it inhabits naturally in the Caspian Sea, Black Sea and the Sea of Azov, and originally in many of the tributaries of these seas. They reach to sexual maturity at 13-23 years (Şener et al., 2005; Memiş et al., 2009).

Production of the fish has mainly relied on aquaculture due to depleted fisheries in the wild from overfishing, weaknesses of control and management measures, and pollution in the past decade (Raymakers and Hoover, 2002). Studies on development and growth had a major role for sturgeons in order to preserve the stocks (Dettlaff and Goncharov, 2002). There is a lack of information in the literature on the growth and farming, although several studies conducted at Russian sturgeon sturgeon species. In Turkey, first production trials of Russian sturgeon performed in the Marmara region in 2002 (Şener et al., 2005). Most of the previous studies on Russian sturgeon were focused on the effects of feeding rate and the growth performance of juveniles. Nathanailides et al. (2002) incubated to Russian sturgeon in zouger jars at $16^{\circ} \mathrm{C}$ and investigated hatching time and post-hatch growth in Russian sturgeon. Şener et al. (2005) investigated effects of dietary lipids on growth and fatty acid composition in Russian sturgeon juveniles. Memiş et al. (2007) determined effects of different diets on growth performance and body composition of Russian sturgeon. Memiş et al. (2009) examined growth and survival rate of Russian sturgeon larvae from fertilized eggs to artificial feeding. Roozbehfar et al. (2012) studied the exploitation of Russian sturgeon from Artemia urmiana nauplii, Daphnia magna and its mixture. On the other hand, development at growth-out phase of Russian sturgeon has not been documented thus far. Within this context, the main objective of the study was to assess the growth performance throughout 5 years. In addition, the present study was also conducted to investigate problems encountered in grow-out phase.

\section{Material and Methods}

Fish samples $(\mathrm{n}=51 ; 2750.88 \pm 351.18 \mathrm{~g}, 80.18 \pm 6.49$ $\mathrm{cm}$ mean \pm SD) were obtained from Russia. Fish were equally numbers stocked into tanks, three replicate tanks, and fed for 5 years. Fish were reared in circular fiberglass tanks with a rearing volume of $40 \mathrm{~m}^{3}$. Each tank contained 17 fish samples. The water flow was $3 \mathrm{~L} \mathrm{~min}^{-1}$ per tank. The oxygen and $\mathrm{pH}$ were measured with YSI model 51 oxygen meter daily. Temperature was measured with a digital thermometer twice a day $\left(8: \underline{.00}-9: \frac{00}{16}, 16: \underline{.0}-17: \underline{.00}\right)$. 
Temperature of the incoming water was $16.92 \pm 4.25^{\circ} \mathrm{C}$. $\mathrm{pH}$ and dissolved oxygen value were $7.70 \pm 0.37$ (7.54 $8.70)$ and $8.14 \pm 1.42(6.43-10.29) \mathrm{mg} \mathrm{L}^{-1}$, respectively. Aerated water in the batches was recirculated and $20 \%$ of the water changed daily. The photoperiod was seasonal changing. Fish were hand-fed with commercial food $(8$ mm extrude trout feed; $45 \% \mathrm{CP}$ : crude protein, $18 \% \mathrm{CF}$ : crude fat, E: energy, $4100 \mathrm{Kcal} / \mathrm{kg}$ ) the same daily ration twice a day, seven days a week. The proximate composition of the experimental diets is shown in Table 1. The amount fed to each tank was recorded. The experiment lasted for 5 years. Fish in the control treatment were fed to satiation throughout the 5 years period.

Each fish was anesthetized (Benzocaine, $50 \mathrm{mg} \mathrm{L}^{-1}$ ), and body weight (BW: body weight; to $0.01 \mathrm{~g}$ ), and fork length (FL: fork length; to $0.1 \mathrm{~cm}$ ) recorded. Specific growth rate (SGR) was calculated as $\left[\left(\operatorname{lnL}_{2}-\operatorname{lnL}_{1}\right) /\left(\mathrm{t}_{2}-\right.\right.$

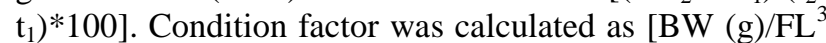
$(\mathrm{cm})]^{* 100}$. Feed conversion ratio (FCR) [dry feed fed $(\mathrm{g}) /$ wet weight gain $(\mathrm{g})]$ were estimated. No mortality occurred during the entire experimental period. Growth, SGR and condition factor among experimental tanks on different periods were tested to analysis of variance.

\section{Results}

Changes of mean body length $(\mathrm{cm})$ and weight $(\mathrm{g})$ of Russian sturgeon A. gueldenstaedtii throughout 5 years are presented in Table 2. The initial mean weight and length of Russian sturgeon were $2750.88 \pm 3.51 \mathrm{~g}$ and $80.18 \pm 6.49 \mathrm{~cm}$, respectively. At the end of the experiment, mean final length and weight were $106.34 \pm 2.79 \mathrm{~cm}$ and $6651.16 \pm 3.16 \mathrm{~g}$. It was determined that there are no significant differences in final weight and length among the experimental tanks $(\mathrm{P}>0.05)$.

Specific growth rate (SGR) of A. gueldenstaedtii at overall was calculated as 1.83. Changes at specific growth rate are presented in Figure 1. During the rearing period of Russian sturgeon, SGR values decreased dramatically from 2.88 to 2.49 .

Changes of condition factor (CF) of A. gueldenstaedtii throughout 5 years are presented in Figure 2. The mean condition factor $(\mathrm{CF})$ at year 1 was 0.52 . The mean condition factor $(\mathrm{CF})$ at overall was 0.51 . The lowest value of condition factor $(\mathrm{CF})$ was determined in $3^{\text {rd }}$ year. $\mathrm{CF}$ considerably decreased to $0.493^{\text {rd }}$ year and then increased to 0.51 again.

Food conversion rate values (FCR) of $A$. gueldenstaedtii are shown in Figure 3. During the rearing period of Russian sturgeon, FCR values fluctuated and the highest value of food conversion rate (FCR) were determined in $4^{\text {th }}$ year.

\section{Discussion}

For Russian Sturgeon A. gueldenstaedtii, there is little available information on feed requirements and growth. Thus far, conducted studies are related to feeding and growth rate on larvae and juveniles. Nathanailides et al. (2002) examined hatching time and post-hatch growth in Russian sturgeon.
Table 1 Proximate composition of experimental diet.

\begin{tabular}{l|c}
\hline \multicolumn{1}{c|}{ Proximate composition } & Percent of dry weight \\
\hline Crude protein (\%) & 45.0 \\
Crude fat (\%) & 18.0 \\
Ash (\%) & 12.0 \\
Crude cellulose (\%) & 3.0 \\
Moisture (\%) & 12.0 \\
Metabolic energy (Kcal/kg) & 4100.0 \\
Calcium / Phosphor (\%) & 2.0 \\
Phosphor (\%) & 1.5 \\
EPA+DHA (\%) & 2.5 \\
Lysine (\%) & 1.8 \\
Methionin +Cystein (min) (\%) & 0.5 \\
BHT (\%) & 1.7 \\
\hline
\end{tabular}

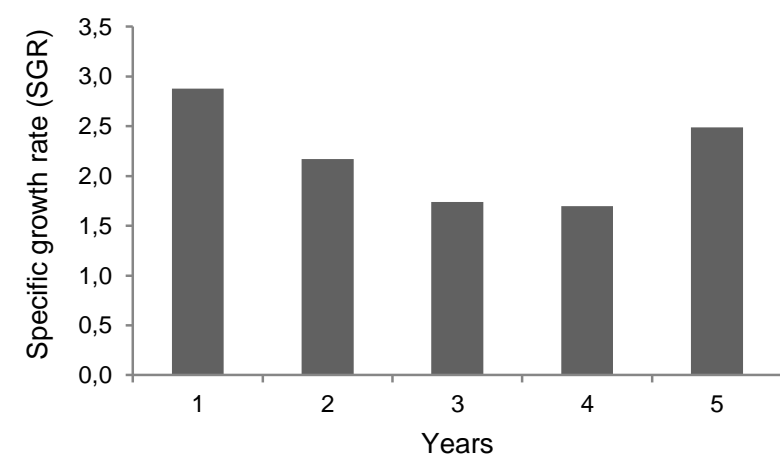

Fig.1 Specific growth rates (SGR) overall (5 years) in Acipenser gueldenstaedtii.

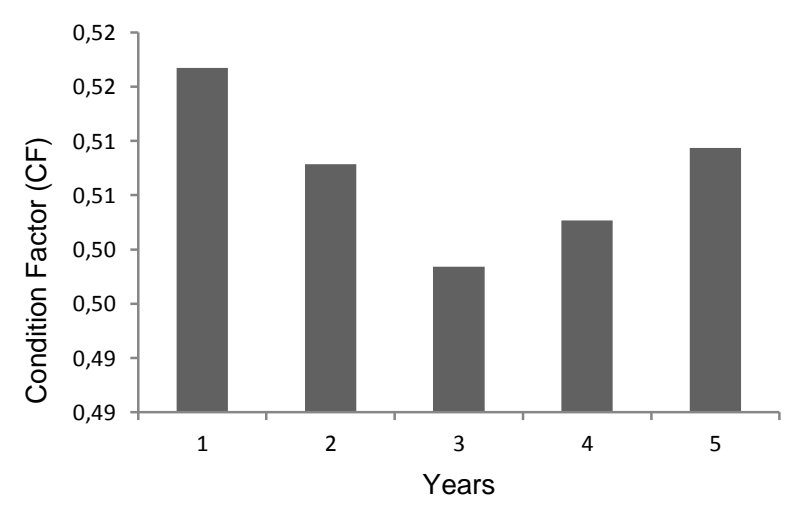

Fig. 2 Condition factor (CF) overall (5 years) in Acipenser gueldenstaedtii.

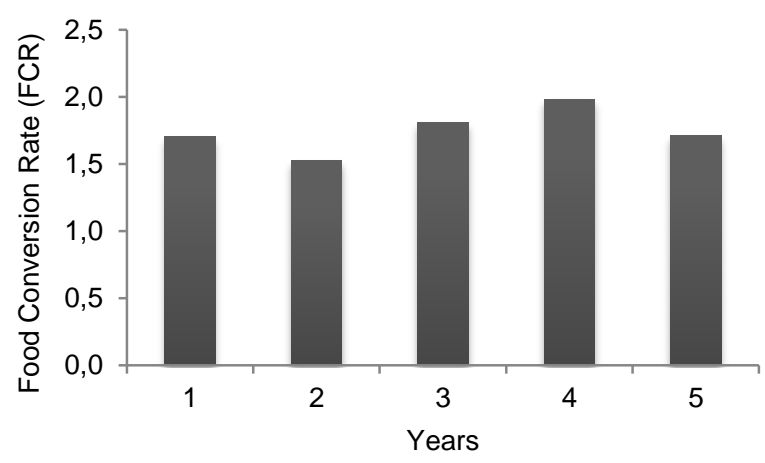

Fig. 3 Feed Conversion Ratio (FCR) overall (5 years) in Acipenser gueldenstaedtii. 
Table 2 Changes of mean body length $(\mathrm{cm})$ and body weight $(\mathrm{g})$ of Acipenser gueldenstaedtii over 5 years $(\mathrm{n}=51)$.

\begin{tabular}{c|rrrrrr}
\hline \multirow{2}{*}{ Years } & \multicolumn{3}{|c}{ Body Length $(\mathrm{cm})$} & \multicolumn{3}{c}{ Body Weight $(\mathrm{g})$} \\
\cline { 2 - 7 } & \multicolumn{1}{|c}{$\min$} & $\max$ & mean \pm SD & $\min$ & $\max$ & mean \pm SD \\
\hline 1 & 80.18 & 89.82 & $89.82 \pm 3.73$ & 2750.88 & 3745.00 & $3280.65 \pm 3.51$ \\
2 & 90.21 & 93.16 & $95.36 \pm 2.04$ & 3948.82 & 4404.71 & $4193.00 \pm 2.06$ \\
3 & 95.35 & 98.71 & $93.16 \pm 1.48$ & 4570.88 & 4793.00 & $4689.98 \pm 1.02$ \\
4 & 98.66 & 101.29 & $100.08 \pm 1.27$ & 4704.66 & 5179.00 & $5094.37 \pm 2.70$ \\
5 & 103.69 & 111.90 & $106.34 \pm 2.79$ & 6318.00 & 7137.00 & $6651.16 \pm 3.16$ \\
\hline
\end{tabular}

Şener et al. (2005) investigated effects of dietary lipids on growth and fatty acid composition in Russian sturgeon juveniles. In different studies, it was also determined effects of different diets on growth performance and body composition of Russian sturgeon (Memiş et al. 2007), growth and survival rate from fertilized eggs to artificial feeding (Memiş et al. 2009) and effect of Artemia urmiana nauplii, D. magna and its mixture on growth (Roozbehfar et al. 2012). However, information on development at growth-out phase of the species is not quite known. Therefore, in this study, growth and development at growth-out phase were monitored throughout 5 years.

Growth is a period of increased length and weight of body and dependent upon fish species, fish size, dietary nutrient content, and duration of feeding trial, feeding regime, social factors and physiological/nutritional state of fish. Nutritional requirements and culture conditions of sturgeon are not quite known (Cristea et al., 2012). For a good growth rate, knowledge of the species-specific physiological requirements and a better technological management are important (Dicu Stroe et al., 2013). In the present study, it was observed low growth rate throughout 5 years. SGR have shown a slower growth rate. The values of growth performance indicators (gain of weight and length, SGR, CF) indicated a decrease. Slow growth of Russian sturgeon may be due to unknowing of optimum culture conditions, stocking density, water quality, and various items related to nutrition and type of culture system. For these reasons, data obtained from the present study have many benefits for conservation of wild stocks, aquaculture production, and for understanding biology of Russian sturgeon $A$. gueldenstaedtii.

The results indicated that Russian sturgeon has high FCR. In the present study, extrude trout feed was used as food. Thus far, studies on feeding of Russian sturgeon have only been performed larvae and juveniles (Şener et al., 2005; Memiş et al., 2007, 2009; Roozbehfar et al., 2012). However, there is no study on effect of diet in growth-out phase. Therefore, most appropriate food type for the species is not known in growth-out phase. For these reasons, trials on effect of different foods are needed to investigate and highly efficient diets should be prepared for fast growth.

\section{Conclusion}

Wild stocks of Russian sturgeon A. gueldenstaedtii have threatened because of pollution, river dams, legal and illegal fishing, and the trade in caviar. Hence, aquaculture of the species has increased in importance. This study will provide benefits for a large-scale production. To further assess the potential grow-out of this species, additional research is needed to investigate for commercial aquaculture.

\section{References}

Cristea V, Dicu MD, Dediu L, Măereanu M, Coadă MT. 2012. The influence of feeding intensity on growth performance of Acipenser stellatus (Pallas 1771) juvenils. Lucrari Stiintifice Journal, Seria Zootehnie, 58: 219-224.

Dicu Stroe MD, Cristea V, Dediu L, Docan A, Grecu IR, Vasilean I. 2013. Effects of stocking density on growth and hematological profile of early juveniles Stellate Sturgeon (A. stellatus Pallas, $1771)$ reared in a "Flow-Through" production system. Anim. Sci. Biotechnol., 46 (2): 250-257.

Dettlaff TA, Goncharov BF. 2002. Contribution of developmental biology to artificial propagation of sturgeon in Russia. J. Appl. Ichthyol., 18 (4-6): 266-270. DOI: 10.1046/j.14390426.2002.00408.x.

Memiş D, Çelikkale MS, Ercan E. 2007. Effects of different diets on growth performance and body composition of Russian sturgeon (Acipenser gueldenstaedtii, Brandt and Ratzenburg, 1833). J. Appl. Ichthyol., 22 (Supplement s1): 287-290. DOI: 10.1111/j.1439-0426.2007.00970.x.

Memiş D, Ercan E, Çelikkale MS, Timur M, Zarkua Z. 2009. Growth and survival rate of Russian sturgeon ( $A$. gueldenstaedtii) larvae from fertilized eggs to artificial feeding. Turk. J. Vet. Anim. Sci., 9: 47-52.

Moini S, Khoshkhoo Zh, Matin RH. 2012. The Iranian (Acipenser persicus) and Russian (Acipenser gueldenstaedtii) sturgeon's fatty acids changes during cold storage. Global Vet., 9 (1): 3841.

Nathanailides C, Tsoumani M, Papazogloy A, Paschos I. 2002. Hatching time and post-hatch growth in Russian sturgeon Acipenser gueldenstaedtii. J. Appl. Ichthyol., 18 (4-6): 651-654. DOI:10.1046/j.1439-0426.2002.00399.x.

Raymakers C, Hoover C. 2002. Acipenseriformes: CITES implementation from Range States to consumer countries. J. Appl. Ichthyol., 18 (4-6): 629-638. DOI: 10.1046/j.14390426.2002.00398.x.

Roozbehfar R, Jamali H, Hematian R. 2012. The potential of Russian Sturgeon (Acipenser gueldenstaedtii) in exploitation of Artemia urmiana in comparison with Daphnia sp. and its mixture. World Appl. Sci. J., 20 (6): 776-780, DOI: 10.5829/idosi.wasj.2012.20.06.6573.

Şener E, Yıldız M, Savaş E. 2005. Effects of dietary lipids on growth and fatty acid composition in Russian Sturgeon (Acipenser gueldenstaedtii) juveniles. Turk. J. Vet. Anim. Sci., 29 (5): 1101-1107 